\section{Isomeric Forms of Complex Acetic Acid}

THE synthesis of 1-carboxy-3-methylcyclohexane-1acetic acid by Higson and Thorpe's method ${ }^{1}$ gave rise to a small amount of the acid, m.p. $163^{\circ}$, originally obtained by oxidation of $\alpha$-keto-3-methylcyclohexane-1 : 1-diacetic acid ${ }^{2}$, accompanied by a low melting point gum which was ultimately resolved into a mixture of two crystalline isomers of this. The application of Lapworth and McRea's synthesis ${ }^{3}$, on the other hand, gave a more satisfactory yield of the acid melting at $163^{\circ}$, accompanied by only small amounts of the other isomers. The isolation of three forms of the acid,<smiles>CCCCCC(CCCCC)(CC(=O)O)C(=O)O</smiles>

is explicable only on the basis of the assumption of a strainless form of the methylcyclohexane ring, and the corresponding acids obtainable from $3: 3$-dimethylcyclohexanone are therefore being investigated in this laboratory. A full report will be published elsewhere in due course.

$$
\begin{aligned}
& \text { Muslim University, } \\
& \text { Aligarh. } \\
& \text { J. Chem. Soc., 89, 1455; } 1906 . \\
& 2 \text { Desai, J. Chem. Soc., 1063; } 1932 . \\
& \text { J. Chem. Soc., 121, } 2754 ; 1922 .
\end{aligned}
$$

\section{Effects Produced on Rats by Synthetic Androsteron} (Male Sex Hormone)

Aт the request of Prof. Ruzicka, I undertook the experimental investigation on male and female rats of the biological properties of androsteron and some of his other allied synthetic preparations. The following are the first results with androsteron.

(1) Androsteron contains both one rat unit of "Comb growth activity" and one rat unit of "whole male sexual activity" (as defined by $\mathrm{me}^{1}$ ) in from 175 to $179 \gamma$, the rat unit approximating to, if not being equal to, the capon unit (Butenandt and Tscherning ${ }^{2}$ and Ruzicka and co-workers ${ }^{3}$ ).

(2) The effect of androsteron in increasing the weight of the atrophied prostate of castrated rats is nearly directly proportional to the dose with doses of from $0.2 \mathrm{mgm}$. to $0.9 \mathrm{mgm}$., after which dose the curve flattens.

(3) The daily dose of $1.8 \mathrm{mgm}$. of androsteron injected into castrated rats for 21 days caused an increase in weight of the atrophied prostate by about 800 per cent and of the seminal vesicles by about 500 per cent, of the penis by about 200 per cent and of the preputial glands by about 180 per cent.

(4) In castrated males and in ovariectomised females androsteron also caused the following changes : a return towards or to normal, a decrease in the weight of the adrenals (hypertrophied after castration); an increase in the weight of the liver, kidney and, in most males, to a slight extent the thyroid (which decreases after castration); the restoration of the normal rate of involution of the thymus ; an increase in the appetite and gain in body weight. Injections into castrated males also increased the weight of the heart (which is slightly decreased by eastration).

In addition to these favourable results on the weight of the organs, histological investigation showed the absence of any toxic effect of androsteron in those organs of castrated rats the structure of which is not considerably changed by castration (liver, kidney and heart) and a return towards or to normal in those organs investigated the microscopical structure of which undergoes severe changes after castration (sexual organs, adrenals).

(5) Androsteron did not cause a return to normal (in weight or histologically) of the hypertrophied hypophysis of castrated males, nor did it produce ostrous in ovariectomised females even when injected in doses of $1.8 \mathrm{mgm}$. for $2 \mathrm{I}$ days. It also had no 'rejuvenating' effect on old male rats in the doses used $(0.1 \mathrm{mgm}$. and $0.9 \mathrm{mgm}$. per day for 21 days).

Repetition of the assay with a second batch of androsteron and of some other experiments are in progress.

Lister Institute of Preventive Medicine,

V. KORENCHEVSKY.

London, S.W.1.

1 Biochem. J., 28, 1498; 1934.

2 Butenandt, A., and Tscherning, K., Z. physiol. Chem., 229, 179 ;

${ }_{3}^{1934}$ Ruzicka, L., Goldberg, M., Meyer, J., Brüngger, H., and Eichenberger, E., Helvetica Chim. Acta, 17, 1395 ; 1934.

\section{A Useful Indicator for the Passage of Food through the Alimentary Tract of Animals}

The following method has been used at this laboratory to indicate the distribution of bacteria in the alimentary tract of the rabbit at various times after they had been given per os. It was found to work very satisfactorily and appears to have several advantages over the various colouring methods which have been used from time to time in observations on the passage of foods through the intestinal tract of domestic animals and birds.

The indicator is Lycopodium powder (used in pharmacy for covering pills) which is composed entirely of the spores of the staghorn moss, Lycopodium clavatum. The powder requires to be placed in slightly soapy water before it can be wetted, but this is not necessary if it is to be mixed with food. Lycopodium spores are easily recognisable under the microscope, but their chief merit as an indicator for the passage of food through the alimentary tract lies in the ease with which they can be recovered from the ingesta by means of the ordinary sugar floatation technique, as used for the recovery of nematode eggs from the fæces. It also has the advantage that a count of the spores can be made by any of the methods used for counting nematode eggs in fæces, and fairly accurate information so obtained post-mortem on the relative amounts of the test dose in various parts of the alimentary tract.

\section{Veterinary Laboratory, \\ Ministry of Agriculture, \\ Weybridge, Surrey. \\ Oxygen Consumption of the Cockroach in Relation to Moulting}

During experiments on the oxygen consumption of Blatella germanica, it was observed that one specimen which was used on the day of its last moult, when it was still pale in colour, had a respiratory rate about 50 per cent higher than the normal. Experiments were accordingly undertaken in which the rate of oxygen consumption of the last 